\title{
Management of portal vein thrombosis in cirrhotic patients enlisted for liver transplantation: From diagnosis to treatment (Review)
}

\author{
EVGENIA KOTSIFA, STYLIANOS KYKALOS, NIKOLAOS MACHAIRAS, \\ NIKOLAOS NIKITEAS and GEORGIOS C. SOTIROPOULOS
} Second Department of Propaedeutic Surgery, Laiko General Hospital, Medical School,
National and Kapodistrian University of Athens, 11527 Athens, Greece

Received February 9, 2021; Accepted July 28, 2021

DOI: $10.3892 /$ br.2021.1470

\begin{abstract}
Portal vein thrombosis (PVT) commonly occurs in patients with cirrhosis. Several classification systems of PVT have been proposed over the years reflecting the challenge in establishing a widely accepted system. To date, PVT has been considered an absolute contraindication for orthotopic liver transplantation (OLT) since it is associated with decreased graft survival and increased patient mortality. Nevertheless, the development of modern surgical techniques has enabled the inclusion of these candidates in OLT waiting lists, since their postoperative results are shown to be comparable to those of patients without PVT. The aim of the present review was to critically appraise the available treatment options for cirrhotic patients enlisted for liver transplantation in the setting of PVT.
\end{abstract}

\section{Contents}

1. Introduction

2. Pathophysiology

3. Diagnosis and classification

4. Management of PVT

5. OLT techniques in cases with PVT classified as Yerdel I and II

6. OLT techniques in cases with PVT classified as Yerdel III

7. OLT techniques in cases with PVT classified as Yerdel VI

8. Outcome of LT in the presence of PVT

9. Conclusion

Correspondence to: Dr Stylianos Kykalos, Second Department of Propaedeutic Surgery, Laiko General Hospital, Medical School, National and Kapodistrian University of Athens, Ag. Thoma 17, 11527 Athens, Greece

E-mail:kykalos@gmail.com

Keywords: portal vein, thrombosis, cirrhosis, liver transplantation, end stage liver disease

\section{Introduction}

Portal vein (PV) thrombosis (PVT) is a disease that is relatively common in patients with liver cirrhosis, especially in those with advanced-stage disease (1). Thrombosis in these patients is more frequently chronic and asymptomatic and, in most cases, diagnosed incidentally during routine examinations or pre-transplant evaluation. Until recently, PVT was considered an absolute contraindication for orthotopic liver transplantation (OLT) since it was associated with decreased graft survival and increased recipient mortality (2). Nevertheless, advances in surgical and medical strategies have contributed towards overcoming this problem, and therefore patients with PVT are no longer excluded from OLT waiting lists (3). The prevalence of PVT in patients on a waiting list for OLT may vary from $5-26 \%$, with reported 1-year de novo PVT rates of $7.4-8.4 \%(4,5)$. The objective of the present review was to briefly discuss and critically appraise the available treatment options for cirrhotic patients enlisted for liver transplantation in the setting of PVT.

\section{Pathophysiology}

The pathophysiology of PVT is multifactorial. Liver fibrosis causes increased intra-hepatic resistance, which results in decreased portal blood flow, and this in-turn predisposes patients to PV stasis and clot formation. Furthermore, portal hypertension can lead to endothelial damage, which constitutes an additional critical risk factor for thrombosis. These factors, combined with a dysregulated hemostasis mechanism, are commonly observed in patients with cirrhosis and may result in PVT (6-8). In patients with cirrhosis, the presence of hepatocellular carcinoma is also considered an important factor associated with PVT formation, not only due to the direct invasion and compression caused by the tumor mass, which is common, but also due to the cancer-induced thrombotic state (6). Moreover, endotoxemia, previous splenectomy and placement of transjugular intrahepatic portosystemic shunt (TIPS), are considered triggering risk factors for thrombus development due to the associated endothelial cell injury and alterations caused to the portal circulation (6). Other thrombotic 
risk factors that have been shown to result in PVT include sex, diabetes mellitus, obesity, non-alcoholic steatohepatitis and decreased portal flow velocity $(<15 \mathrm{~cm} / \mathrm{sec})(9)$.

\section{Diagnosis and classification}

PVT may be acute or chronic. Patients with cirrhosis and PVT are typically asymptomatic due to the gradual presentation and slower evolution of the disease that results in the formation of collateral circulation (10). The majority of the cases are diagnosed incidentally during routine examinations or pre-OLT evaluation. Ultrasound and Doppler ultrasound are the imaging methods of choice that are used to diagnose PVT (11). Ultrasound indicates hyperechoic material within the vein and absent flow on pulsed Doppler, which is suggestive of chronic PVT (12). The application of these methods provides information on the direction of the flow and may be used to measure the exact velocity of the PV trunk and intrahepatic branches (8). Alternatively, co-axial tomography and magnetic resonance imaging angiography can also be used, providing additional information regarding the PV and the neighboring vessels (Table I). Given the high incidence and clinical impact of PVT on OLT, in conjunction with the often unavoidable prolonged period on a waiting list, repetitive screening of enlisted patients (every 6 months)is strongly recommended (13). Doppler ultrasound appears to be the most feasible modality for such narrow screening (12). Over the past 20 years, several classification systems have been proposed for PVT, each with their own advantages and disadvantages. The most well recognized classification system remains that proposed by Yerdel et al (14) in 2000, which represents an anatomical grading system (Fig. 1). A subsequent classification system was proposed by the Baveno VI Consensus, which has been widely adopted, and includes underlying liver disease but not liver functional status (Table II) (11). More recently, Sarin et al (15) introduced a novel classification system that included functional aspects of PVT, such as symptomatology at presentation and duration of symptoms. The challenge in establishing a widely accepted classification system reflects the complexity in defining and describing this clinical entity and the continuous effort in creating a communication formula, which can be applied worldwide and can provide effective screening and treatment protocols for these high-risk patients.

However, it should be highlighted that the use of this novel classification proposal by the Baveno IV Consensus or Sarin consensus rather than Yerdel's classification, seems to offer no clinical advantage or improvement in decision-making during OLT of patients with PVT. It is noteworthy that classifications incorporating functional aspects of PVT do not actually influence the selection of portal inflow to the graft, since surgical techniques are anatomically dependent and highly individualized $(16,17)$.

\section{Management of PVT}

The management of PVT in the setting of OLT is initiated preoperatively with three basic options (4). Initially, systematic anticoagulation agents, such as vitamin $\mathrm{K}$ antagonists and low molecular weight heparin (LMWH) are administered particularly in acute PVT or in cases that have a suspected extension of a chronic thrombus (18). Despite the low rate of recanalization in patients with complete thrombosis, the efficacy of these agents is well demonstrated in partial thrombosis cases with reported success rates of $75 \%(4,5)$. The second approach involves the placement of TIPS in order to re-establish PV flow and decrease portal hypertension symptoms by producing a low resistance shunt between the PV and the hepatic vein connection (6). Despite the lack of robust evidence supporting either anticoagulation or TIPS as a first line approach to treat PVT, TIPS appears to be more effective in patients with extended thrombosis and cavernoma (6). Luca et al (19) reported complete recanalization in $57 \%$ of patients and partial recanalization in $30 \%$ of patients with PVT treated with TIPS. The TIPS dysfunction rate after 12 and 24 months was 38 and $85 \%$ for the bare stent, and 21 and 29\% for the covered stent, respectively (Table III) (19).

Finally, thrombolysis represents a third approach of preoperative PVT management. The supporting literature is weak with only a limited number of cases reported (20). The surgical technique of OLT in the setting of PVT is tailored based on the extent of the thrombus, the presence of pre-existing portosystemic shunts (surgical or spontaneous) and the expertise of the surgeon and center in performing LT. For practical reasons, all possible reconstruction techniques are primarily described according to the classical classification proposed by Yerdel et al (14).

\section{OLT techniques in cases with PVT classified as YerdelI and II}

Patients with PVT classified as Yerdel I and II can be adequately treated by thrombectomy (simple, with eversion or with the use of a Fogarty catheter), suggesting that a complicated reconstruction is not required; if the thrombus extents to the superior mesenteric or the splenic vein, a complete exposure of the vessels may be required. However, this procedure entails the risk of retro pancreatic hemorrhages (21). In certain cases, thromboendovenectomy (removing of the intima) is performed in order to achieve adequate inflow to the allograft (21). If none of the aforementioned methods are efficient, the affected portion of the vein is removed. Reconstruction with end-to-end portal anastomosis, or reconstruction using an interposition vein graft is performed (22). An additional anastomosis can be performed just underneath the primary end-to-end portal anastomosis, with or without an interposition graft of a nearby portal branch, such as the coronary gastric vein or of an arterial vessel. This aims to reinforce the blood flow (22).

\section{OLT techniques in cases with PVT classified as Yerdel III}

In patients with total PV obstruction and thrombus extension in the proximal superior mesenteric vein (SMV), a complete thrombectomy is usually inadequate or not even feasible. In these cases, a jump vein graft can be anastomosed directly to the donor PV cephalad and at the distal free part of the SMV caudal. A free segment of donor iliac vein, which is placed anterior to the pancreas and posterior to the stomach, may serve as a suitable vein graft for this type of reconstruction $(4,22)$. An artificial graft can also be used, originating either from the SMV or the inferior mesenteric vein (23). 
Table I. Advantages and disadvantages of imaging modalities.

\begin{tabular}{lll}
\hline Imaging mode & \multicolumn{1}{c}{ Advantages } & \multicolumn{1}{c}{ Disadvantages } \\
\hline Ultrasound-Doppler & Direction of flow & Radiologist's expertise \\
& $\begin{array}{l}\text { Exact velocity measurement } \\
\text { Least expensive method } \\
\text { Extension of thrombus } \\
\end{array}$ & \\
& Neighboring vessels imaging & \\
& Bland vs. tumor thrombus & X-ray exposure \\
& Shunts imaging & Nephroxicity \\
Magnetic resonance imaging angiography & Extension of thrombus & \\
& Neighboring vessels imaging & \\
& Superior in detecting partial thrombosis & Claustrophobia \\
& Resectability of neoplasm & Most expensive method \\
\end{tabular}

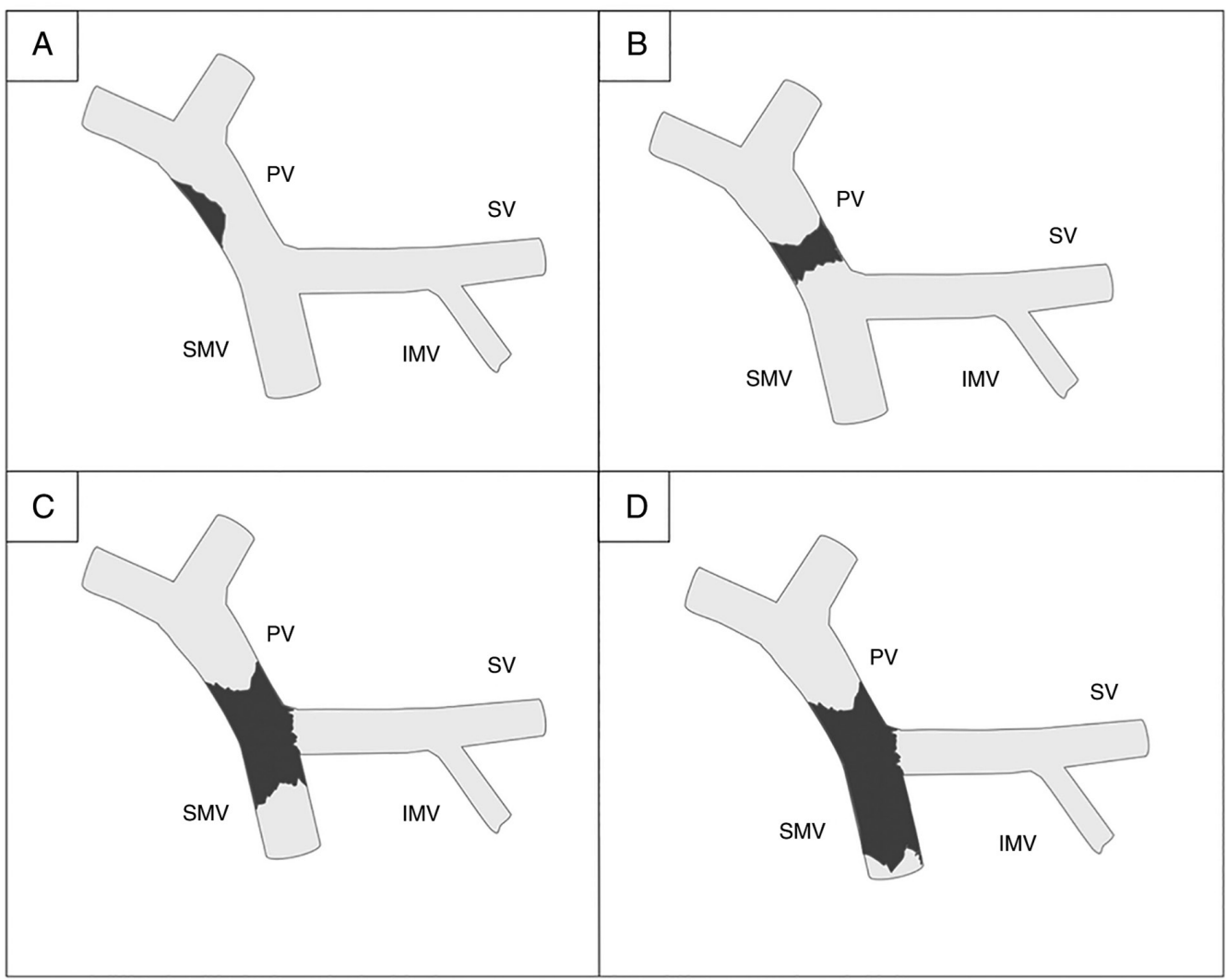

Figure 1. Visualization of Yerdel classification of PVT. (A) Grade I; (B) grade II; (C) grade III; and (D) grade IV. PVT, portal vein thrombosis; PV, portal vein; SMV, superior mesenteric vein; SV, splenic vein; IMV, inferior mesenteric vein.

Anastomosis can be made in a side-to-end or an end-to-end manner in cases where the distal end of the graft (synthetic or not) is anastomosed with the SMV. A reasonable alternative option described by Magistri et al (24) involves the placement of an extra-anatomic jump graft from the right colic vein with donor iliac vein interposition.

\section{OLT techniques in cases with PVT classified as Yerdel IV}

In patients with diffuse splanchnic thrombosis, the indicated technique depends on the presence of pre-existing surgical or spontaneous portosystemic shunts. Cases with pre-existing portosystemic shunts, adequate flow and vessel diameter can be often used for portal anastomosis. The reconstruction alternatives include the use of enlarged veins (coronary, right/middle colic, ileocolic and right gastroepiploic), or even pericholedochal varices for anastomosis to graft PV. Moreover, in case of a patent splenorenal shunt, the left renal vein can be disconnected at the junction with the vena cava inferior (IVC) and anastomosed (directly or even with an interposition graft) to the PV of the graft. A sufficient mesenteriocaval shunt may also be used in same manner (16,25-28). 
Table II. Baveno VI-classification of PVT.

\begin{tabular}{|c|c|}
\hline Class & Description \\
\hline \multicolumn{2}{|l|}{ Site of PVT } \\
\hline Type 1 & Only trunk \\
\hline Type $2 \mathrm{a}$ & Only branch \\
\hline Type $2 b$ & Both branches \\
\hline Type 3 & Trunk and branches \\
\hline \multicolumn{2}{|l|}{ Presentation } \\
\hline Recent (R) & Clinical presentation and presence of hyperdense thrombus on imaging \\
\hline Chronic (Ch) & $\begin{array}{l}\text { With portal cavernoma and clinical features of portal hypertension, } \\
\text { no hyperdense thrombus }\end{array}$ \\
\hline \multicolumn{2}{|c|}{ Type of underlying liver disease } \\
\hline $\mathrm{C}$ & Cirrhotic \\
\hline $\mathrm{N}$ & Non-cirrhotic liver disease \\
\hline $\mathrm{H}$ & Hepatocellular carcinoma and other local malignancies \\
\hline $\mathrm{L}$ & Post-liver transplant \\
\hline A & Absence of underlying liver disease \\
\hline \multicolumn{2}{|c|}{ Degree of portal venous system occlusion } \\
\hline I & Incomplete: Flow visible in PV lumen through imaging \\
\hline $\mathrm{T}$ & Total: No flow visible in PV lumen on imaging \\
\hline \multicolumn{2}{|c|}{ Extent of PV system occlusion } \\
\hline $\mathrm{S}$ & Splenic vein \\
\hline M & Mesenteric \\
\hline SM & Both splenic vein and mesenteric \\
\hline
\end{tabular}

PVT, portal vein thrombosis; PV, portal vein.

Table III. Anticoagulation vs. TIPS.

\begin{tabular}{lll}
\hline Treatment & \multicolumn{1}{c}{ Advantages } & \multicolumn{1}{c}{ Disadvantages } \\
\hline Anticoagulation & $\begin{array}{l}\text { Non invasive } \\
\text { Proven efficacy in portal vein } \\
\text { thrombosis } \\
\text { Reversibility prior to OLT }\end{array}$ & $\begin{array}{l}\text { Difficulties in dosage impairment at patients with renal failure } \\
\text { Increased hemorrhage risk }\end{array}$ \\
& $\begin{array}{l}\text { Feasible in 70-80\% of patients } \\
\text { Recanalization achieved in cases } \\
\text { TIPS }\end{array}$ & $\begin{array}{l}\text { Low percentages of recanalization in cases of complete thrombosis } \\
\text { Contraindication at patients with high MELD score }\end{array}$ \\
& Low percentage of dysfunction & Increased hepatic encephalopathy risk \\
\hline
\end{tabular}

TIPS, transjugular intrahepatic portosystemic shunt; OLT, orthotopic liver transplant; MELD, model for end-stage liver disease.

All these types of reconstruction are actually considered as physiological since the graft inflow is supplied by the blood of the PV system. The patients with an existing portosystemic shunt that drains directly in the IVC may be treated with cavoportal hemitransposition, which represents an alternative option $(25,26)$.

In the absence of pre-existing shunts, alternative options are limited. The three feasible techniques are: Cavoportal hemitransposition, renoportal anastomosis (in end-to-end manner with the left renal vein) and PV arterializations (22,29-31).
Multivisceral transplantation (MVT) including the liver, small bowel, stomach and the pancreas has also been proposed as another alternative. With the exception of MVT, all other reconstructions are non-physiological since the inflow to the liver graft is provided by the systemic venous or arterial systems (32).

If a cavoportal hemitransposition is recommended, the anastomosis can be performed in an end-to-end or in aside-to-end manner. The latter enables the IVC to be ligated or partially narrowed (maintaining a bloodstream to right 
ventricle) at a higher level, in order to enhance the blood inflow towards graft PV. However, if a porto-portal anastomosis (with inadequate flow) can be performed, an additional side-to-end porto-cavalanastomosis, with or without venous interposition graft, (above the level of the primary anastomosis) may also support the graft supply $(29,30)$.

A cavoportal hemitransposition may be accompanied by several complications, primarily due to untreated portal hypertension. Moreover, the occurrence of refractory ascites and the risk of variceal bleeding can cause congestion of the systemic venous system, potentially leading to gradual impairment of kidney function and excessive peripheral edema. Finally, postoperative gastrointestinal bleeding or development of vena cava thrombosis may also occur (33).

The PV arterialization is mainly considered a salvage procedure in cases of complete absence of portal flow. It has been also proposed in revision operations following OLT complicated with extensive postoperative portal thrombosis. In selected cases, an arterial branch of graft celiac trunk may be used to establish an additional anastomosis to the PV in order to support its primarily insufficient flow (31). The first referrals to partial or even complete PV arterialization involved usage of a donor's splenic artery stump and preparation of an end-to-side anastomosis between the subrenal aorta and the PV of the liver graft with interposition of the donor's iliac artery graft $(22,31)$. It should be noted that in cases of arterialization, the portal hypertension and its associated complications cannot be overcome. Furthermore, the liver graft lacks nutritional factors derived from the splanchnic venous system. Finally, due to increased intraparenchymal portal pressure, arterialization is associated with aneurysmatic malformations of intrahepatic portal branches and progressive liver fibrosis $(31,34)$.

The complex procedure of MVT causes re-establishment of the blood flow by anastomosing the donor's celiac trunk with the recipient's infrarenal aorta (35). The first successful case of MVT was described in 2002 by Florman et al (34) in a patient with diffuse visceral splanchnic thrombosis and protein $\mathrm{C}$ deficiency. A total of 25 cases with MVT for diffuse PVT have been previously reported. The actual patient survival was 80 , 72 and $72 \%$ at 1-, 3- and 5 years, respectively (36).

In the early postoperative period, patients should be treated with LMWH. Long-term anticoagulation therapy is not indicated in patients with anatomical end-to end portal anastomosis and adequate portal flow, given the absence of a thrombophilic condition. The available data regarding the long-term use of anticoagulation agents in cases with non-anatomical anastomosis for extended thrombosis with a significantly higher risk of re-thrombosis are limited (6).

\section{Outcome of LT in the presence of PVT}

Patients with PVT undergoing more complex operations are at high-risk for various complications, affecting both graft and patient survival. Recurrence of thrombosis ranges from 4-39\% amongst published studies during the early post-operative period (37-39). It should be noted that PVT recurrence within the early postoperative period usually leads to graft loss, whereas a delayed occurrence is mostly associated with re-development of portal hypertension. These patients have a two-fold increased overall risk of post-LT vascular thrombosis (in general) compared with those transplanted without PVT. Furthermore, PVT is considered an independent risk factor for thrombosis of the hepatic artery (38). Higher rates of PV re-thrombosis are primarily observed in cases of primary PVT initially staged as Yerdel IV. Furthermore, the use of vascular grafts during reconstruction is accompanied by significant risk of re-thrombosis ( $17 \%$ of cases) $(38,39)$. However the risk associated with the presence of vein grafts appears to affect only the early postoperative period (37).

In addition to PVT stage Yerdel IV and the use of vascular grafts, several additional predisposing factors for re-thrombosis have been described. More specifically, incomplete thrombectomy, low postoperative portal flow, the presence of ascites and non-anatomical anastomoses are associated with higher re-thrombosis rates (40). Several types of vessel grafts can be used during OLT in cases of severe PVT. Specifically, cadaveric-cryopreserved veins and arteries, autologous veins or artificial grafts, such as polytetrafluoroethylene, may all serve as potential grafts in cases of reconstruction. Intima injury of cryo-preserved vessels, graft kinking or graft length excess are risk factors predisposing an individual to re-thrombosis (40). Several studies have shown that the aforementioned grafts all have similar efficacy $(23,41,42)$. Although autologous vessels are not immunogenic, cadaveric vessels are much easier to obtain. Moreover, artificial grafts are considered foreign bodies (40). Taking into account the low blood flow in the portal venous system, the long-term patency of artificial grafts remains questionable. In patients with obesity, refractory ascites or increased intra-abdominal pressure, such as in cases of portorenal shunts, artificial or arterial grafts are suggested, since vein grafts are more compressible $(40,43)$.

The clinical impact of PVT on patient and graft survival following OLT was assessed in a US-based retrospective cohort study (Organ Procurement and Transplant Network database) including all adult patients that underwent a primary OLT between 2002 and 2014 (44). Data analysis revealed that the presence of PVT either at listing or during OLT exhibited a significantly negative effect on both patient and graft survival following OLT. Moreover, cases with long standing PVT exhibited significantly worse survival rates compared with that of new cases of PVT (7). A possible explanation of these findings is the fact that complete removal of a new thrombus during OLT is more likely to be successful compared with removal of an old and firmly organized clot.

A recent meta-analysis of 44 studies focused on the mortality of OLT recipients with PVT (45). The 30-day and 1-year mortality rates were significantly higher in recipients with PVT than in those without PVT [odds ratio (OR) 2.29; $\mathrm{P}<0.0001$ and $\mathrm{OR} 1.38 ; \mathrm{P}<0.0001$, respectively]. In addition, the parameters 30-day mortality (four relevant studies) and 1-year mortality (two relevant studies) were higher in patients with complete PVT compared with those noted in patients with partial PVT (OR 5.65; $\mathrm{P}=0.001$ and $\mathrm{OR} 2.48 ; \mathrm{P}=0.05$, respectively).

\section{Conclusion}

The prevalence of PVT amongst patients on waiting lists is considerably high. Close follow-up of enlisted patients is of cardinal importance in order to detect and initiate the 
recommended medical or even radiological management regimes in cases with PVT. PVT is no longer considered an absolute contraindication for OLT. Due to the development of modern surgical techniques combined with anticoagulation therapy, the postoperative results of patients with partial or low grade PVT are comparable to those noted in patients without PVT. Patients with PVT undergoing OLT should be referred to highly experienced centers due to the complexity of venous reconstructions that are occasionally essential to be performed.

\section{Acknowledgements}

Not applicable.

\section{Funding}

No funding was received.

\section{Availability of data and materials}

Not applicable.

\section{Authors' contributions}

EK, SK and NN conceived and designed the study. EK, NM and GCS drafted the manuscript. EK, NM, GCS and NN revised the manuscript for important intellectual content. All authors have read and approved the final manuscript. Data authentication is not applicable.

\section{Ethics approval and consent to participate}

Not applicable.

\section{Patient consent for publication}

Not applicable.

\section{Competing interests}

The authors declare that they have no competing interests.

\section{References}

1. Basit SA, Stone CD and Gish R: Portal vein thrombosis. Clin Liver Dis 19: 199-221, 2015.

2. Rodriguez-Castro KI, Porte RJ, Nadal E, Germani G, Burra P and Senzolo M: Management of nonneoplastic portal vein thrombosis in the setting of liver transplantation: A systematic review. Transplantation 94: 1145-1153, 2012.

3. Qi X, Dai J, Jia J, Ren W, Yang M, Li H, Fan D and Guo X: Association between portal vein thrombosis and survival of liver transplant recipients: A systematic review and meta-analysis of observational studies. J Gastrointestin Liver Dis 24: 51-59, 2015.

4. Francoz C, Valla D and Durand F: Portal vein thrombosis, cirrhosis, and liver transplantation. J Hepatol 57: 203-212, 2012.

5. Conzen KD and Pomfret EA: Liver transplant in patients with portal vein thrombosis: Medical and surgical requirements. Liver Transpl 23: S59-S63, 2017.

6. Mantaka A, Augoustaki A, Kouroumalis EA and Samonakis DN: Portal vein thrombosis in cirrhosis: Diagnosis, natural history, and therapeutic challenges. Ann Gastroenterol 31: 315-329, 2018.

7. Montenovo M, Rahnemai-Azar A, Reyes J and Perkins J: Clinical impact and risk factors of portal vein thrombosis for patients on wait list for liver transplant. Exp Clin Transplant 16: 166-171, 2018
8. Intagliata NM, Caldwell SH and Tripodi A: Diagnosis, development, and treatment of portal vein thrombosis in patients with and without cirrhosis. Gastroenterology 156: 1582-1599, 2019.

9. Zocco MA, Di Stasio E, De Cristofaro R, Novi M, Ainora ME, Ponziani F, Riccardi L, Lancellotti S, Santoliquido A, Flore R, et al: Thrombotic risk factors in patients with liver cirrhosis: Correlation with MELD scoring system and portal vein thrombosis development. J Hepatol 51: 682-689, 2009.

10. Chawla Y, Duseja A and Dhiman RK: Review article: The modern management of portal vein thrombosis. Aliment Pharmacol Ther 30: 881-894, 2009.

11. Faccia M, Ainora ME, Ponziani FR, Riccardi L, Garcovich M, Gasbarrini A, Pompili M and Zocco MA: Portal vein thrombosis in cirrhosis: Why a well-known complication is still matter of debate. World J Gastroenterol 25: 4437-4451, 2019.

12. Harding DJ, Perera MT, Chen F, Olliff S and Tripathi D: Portal vein thrombosis in cirrhosis: Controversies and latest developments. World J Gastroenterol 21: 6769-6784, 2015.

13. de Franchis R and Faculty BVI: Expanding consensus in portal hypertension: Report of the baveno VI consensus workshop: Stratifying risk and individualizing care for portal hypertension. J Hepatol 63: 743-752, 2015.

14. Yerdel MA, Gunson B, Mirza D, Karayalçin K, Olliff S, Buckels J, Mayer D, McMaster P and Pirenne J: Portal vein thrombosis in adults undergoing liver transplantation: Risk factors, screening, management, and outcome. Transplantation 69: 1873-1881, 2000.

15. Sarin SK, Philips CA, Kamath PS, Choudhury A, Maruyama H, Nery FG and Valla DC: Toward a comprehensive new classification of portal vein thrombosis in patients with cirrhosis. Gastroenterology 151: 574-577, 2016.

16. Bhangui P, Lim C, Levesque E, Salloum C, Lahat E, Feray C and Azoulay D: Novel classification of non-malignant portal vein thrombosis: A guide to surgical decision-making during liver transplantation. J Hepatol 71: 1038-1050, 2019.

17. Mancuso A: Classification of portal vein thrombosis in cirrhosis. Gastroenterology 152: 1247, 2017.

18. Loudin M and Ahn J: Portal vein thrombosis in cirrhosis. J Clin Gastroenterol 51: 579-585, 2017.

19. Luca A, Miraglia R, Caruso S, Milazzo M, Sapere C, Maruzzelli L, Vizzini G, Tuzzolino F, Gridelli B and Bosch J: Short- and long-term effects of the transjugular intrahepatic portosystemic shunt on portal vein thrombosis in patients with cirrhosis. Gut 60 : 846-852, 2011.

20. De Santis A, Moscatelli R, Catalano C, Iannetti A, Gigliotti F, Cristofari F, Trapani S and Attili AF: Systemic thrombolysis of portal vein thrombosis in cirrhotic patients: A pilot study. Dig Liver Dis 42: 451-455, 2010.

21. Molmenti EP, Roodhouse TW, Molmenti H, Jaiswal K, Jung G, Marubashi S, Sanchez EQ, Gogel B, Levy MF, Goldstein RM, et al: Thrombendvenectomy for organized portal vein thrombosis at the time of liver transplantation. Ann Surg 235: 292-296, 2002.

22. Stieber AC, Zetti G, Todo S, Tzakis AG, Fung JJ, Marino I, Casavilla A, Selby RR and Starzl TE: The spectrum of portal vein thrombosis in liver transplantation. Ann Surg 213: 199-206, 1991.

23. Hwang HP, Yang JD, Bae SI, Hwang SE, Cho BH and Yu HC: Usefulness of artificial jump graft to portal vein thrombosis in deceased donor liver transplantation. Yonsei Med J 56: 586-590, 2015.

24. Magistri P, Tarantino G, Olivieri T, Pecchi A, Ballarin R and Di Benedetto F: Extra-anatomic jump graft from the right colic vein: A novel technique to manage portal vein thrombosis in liver transplantation. Case Rep Surg 2018: 4671828, 2018.

25. Davidson BR, Gibson M, Dick R, Burroughs A and Rolles K: Incidence, risk factors, management, and outcome of portal vein abnormalities at orthotopic liver transplantation. Transplantation 57: 1174-1177, 1994.

26. Rudroff $\mathrm{C}$ and Scheele J: The middle colic vein: An alternative source of portal inflow in orthotopic liver transplantation complicated by portal vein thrombosis. Clin Transplant 12: 538-542, 1998.

27. Kato T, Levi DM, DeFaria W, Nishida S, Pinna A, Nery J and Tzakis AG: A new approach to portal vein reconstruction in liver transplantation in patients with distal splenorenal shunts. Transplant Proc 33: 1326, 2001.

28. Manzia TM, Fazzolari L, Manuelli M, Pellicciaro M, Baiocchi L and Tisone G: Liver transplantation in a patient with complete portal vein thrombosis, is there a surgical way out? A case report. Ann Med Surg (Lond) 11: 5-8, 2016. 
29. Tzakis AG, Kirkegaard P, Pinna AD, Jovine E, Misiakos EP, Maziotti A, Dodson F, Khan F, Nery J, Rasmussen A, et al: Liver transplantation with cavoportal hemitransposition in the presence of diffuse portal vein thrombosis. Transplantation 65: 619-624, 1998.

30. Azoulay D, Hargreaves GM, Castaing D and Bismuth H: Caval inflow to the graft: A successful way to overcome diffuse portal system thrombosis in liver transplantation. J Am Coll Surg 190: 493-496, 2000

31. Erhard J, Lange R, Giebler R, Rauen U, de Groot H and Eigler FW: Arterialization of the portal vein in orthotopic and auxiliary liver transplantation. A report of three cases. Transplantation 60: $877-879,1995$.

32. Vianna R and Beduschi T: Multivisceral transplantation for diffuse splanchnic venous thrombosis. Curr Opin Organ Transplant 21: 201-208, 2016

33. Selvaggi G, Weppler D, Nishida S, Moon J, Levi D, Kato T and Tzakis AG: Ten-year experience in porto-caval hemitransposition for liver transplantation in the presence of portal vein thrombosis. Am J Transplant 7: 454-460, 2007.

34. Florman SS, Fishbein TM, Schiano T, Letizia A, Fennelly E and DeSancho M: Multivisceral transplantation for portal hypertension and diffuse mesenteric thrombosis caused by protein $\mathrm{C}$ deficiency. Transplantation 74: 406-407, 2002.

35. Tekin A, Beduschi T, Vianna R and Mangus RS: Multivisceral transplant as an option to transplant cirrhotic patients with severe portal vein thrombosis. Int J Surg 82S: 115-121, 2020

36. Vianna RM, Mangus RS, Kubal C, Fridell JA, Beduschi T and Tector AJ: Multivisceral transplantation for diffuse portomesenteric thrombosis. Ann Surg 255: 1144-1150, 2012.

37. Nikitin D, Jennings LW, Khan T, Vasani S, Ruiz R, Sanchez EQ, Chinnakotla S, Levy MF, Goldstein RM and Klintmalm GB: Twenty years' follow-up of portal vein conduits in liver transplantation. Liver Transpl 15: 400-406, 2009.
38. Kim SJ, Yoon YC, Park JH, Oh DY, Yoo YK and Kim DG: Hepatic artery reconstruction and successful management of its complications in living donor liver transplantation using a right lobe. Clin Transplant 25: 929-938, 2011

39. Rhu J, Choi GS, Kwon CHD, Kim JM and Joh JW: Portal vein thrombosis during liver transplantation: The risk of extra-anatomical portal vein reconstruction. J Hepatobiliary Pancreat Sci 27: 242-253, 2020.

40. Ozer A, Aktas H, Yilmaz TU, Can MG, Gurluler E, Yildiz I and Emiroglu R: Liver transplant in patients with portal vein thrombosis: The experience of 55 patients. Exp Clin Transplant 8: doi: $10.6002,2019$.

41. Llado L, Fabregat J, Castellote J, Ramos E, Torras J, Jorba R, Garcia-Borobia F, Busquets J, Figueras J and Rafecas A: Management of portal vein thrombosis in liver transplantation: Influence on morbidity and mortality. Clin Transplant 21: 716-721, 2007.

42. Pomposelli JJ, Akoad M, Khwaja K, Lewis WD, Cheah YL, Verbesey J, Jenkins RL and Pomfret EA: Evolution of anterior segment reconstruction after live donor adult liver transplantation: a single-center experience. Clin Transplant 26: 470-475, 2012.

43. Kim SJ, Kim DG, Park JH, Moon IS, Lee MD, Kim JI, Yoon YC and Yoo YK: Clinical analysis of living donor liver transplantation in patients with portal vein thrombosis. Clin Transplant 25: $111-118,2011$

44. Ponziani FR, Zocco MA, Senzolo M, Pompili M, Gasbarrini A and Avolio AW: Portal vein thrombosis and liver transplantation: Implications for waiting list period, surgical approach, early and late follow-up. Transplant Rev (Orlando) 28: 92-101, 2014.

45. Zanetto A, Rodriguez-Kastro KI, Germani G, Ferrarese A, Cillo U, Burra P and Senzolo M: Mortality in liver transplant recipients with portal vein thrombosis-an updated meta-analysis. Transpl Int 31: 1318-1329, 2018. 